Proceedings

\title{
Determination of the Thermally Comfortable Air Temperature with Consideration of Individual Clothing and Activity as Preparation for a New Smart Home Heating System
}

\author{
Alexander Peikos * and Carole Binsfeld \\ Chair of Building Physics, TUM Department of Civil, Geo and Environmental Engineering, \\ Technical University of Munich, 80333 München, Germany; Carole.Binsfeld@tum.de \\ * Correspondence: alexander.peikos@tum.de; Tel.: +49-089-289-25757 \\ + Presented at the 12th International Conference on Ubiquitous Computing and Ambient Intelligence \\ (UCAmI 2018), Punta Cana, Dominican Republic, 4-7 December 2018.
}

Published: 23 October 2018

\begin{abstract}
The aim of this paper is to determine a thermally comfortable air temperature in an automated living room. This calculated temperature should serve as input for a user-specific and dynamic heating control in an automated living space. In addition to the usual physical factors (air temperature, humidity, air velocity and radiation temperature), individual clothing and activity should be taken into account. The calculation of such a temperature is based on different methods and indices which are usually used for the evaluation of the thermal comfort. The thermal insulation of the worn clothing is determined by 3 different methods. These is a radio frequency identification system, a thermal imaging camera system and a theoretical calculation of the clothing likely to be worn based on temperature data. The activity performed is only taken into account indirectly through the generated heart rate. All these methods are ultimately very well suited for use in temperature regulation in an automated home, but require further research and extensive evaluation.
\end{abstract}

Keywords: Smart Home; Thermal Comfort; Predicted Mean Vote; Radio Frequency Identification

\section{Introduction}

Buildings are built for people, so a central part of any building concept is knowing what people find comfortable [1]. Thermal comfort is of decisive importance for the well-being inside a building [2]. This is a subjective measure of sensation, because the state of thermal comfort can be understood as satisfaction with the thermal environment $[2,3]$. This satisfaction means that a person in a room does not want a change in physical parameters (air temperature, radiation temperature, air velocity and humidity) and clothing for a given activity [2,4].

In the future the room air temperature should be regulated with the help of conventional heating systems coupled to a Smart Home, such as underfloor heating systems, so that the occupant experiences this feeling of satisfaction with the thermal environment for every given combination of clothing and activity. A smart home is a home that is intelligent enough to provide the residents with a comfortable life by means of technology. Such a home knows the needs of the users or can capture them individually and react accordingly. Thus, the basic requirement for a smart home is the creation of an interactive space in which all mechanical and digital devices are connected to communicate with each other and with the user $[5,6]$. There are almost no limits to the possible applications for 
integrating any devices in a home into a building automation system. The most important functions of an intelligent home can be summarized as follows:

- Comfort functions

- Health functions

- Energy management functions

- Multimedia functions

- Safety functions

The regulation of the room climate and the associated feeling of thermal comfort combines comfort functions with health functions and can make an additional contribution to energy management functions through possible energy savings. In order to create an optimal indoor climate for the occupant, all influencing variables relevant to the indoor climate must be recorded with sensors inside the room. In addition, it must be possible to record the individual clothing as well as the activity carried out at that particular moment.

\subsection{State of the Art}

The current handling of the thermal comfort, as well as the registration of the worn clothing and the carried out activity in the automated living space takes place to a large extent on the basis of user profiles. For example, the time of the day at which the user is at home and what temperature preferences he has (preferably warmer or cooler) are recorded. By detecting all necessary physical parameters in the room, the Smart Home can set a presumably comfortable temperature for the user. If the user independently changes this temperature set by the system, the change is recorded and the next time an adjusted temperature is set automatically. The system learns, based on habitual profiles, which temperature range is thermally comfortable for an individual [7]. Such a user profile helps to regulate the room climate in situations where a decision has to be made, for example whether the current temperature is comfortable for the user in a specific room or not [8]. However, in this procedure, neither the individually worn clothing nor the activity actually carried out is taken into account.

Other approaches try to guess the respective activity by means of motion sensors. It can be determined whether a person is currently moving in the room and the according energy consumption can be calculated using the speed of movement. If the person detected by a sensor does not move in a room for a long period of time, the energy consumption for the individual activity can be determined on the basis of typical activities for this room using the energy consumption listed in ISO 8996 [9]. For example, if a person is in the bedroom at a certain time of day for a longer period of time, the system can assume that the person in the room is sleeping and therefore has an energy consumption of 0.8 met [10].

On the other hand, there is currently no approach that takes into account the clothing worn individually by a person. This is only taken into account with seasonal averages, for example 0.5 clo in summer and 0.8 clo in winter.

\subsection{Aim and Objectives}

The aim of this work is to determine a thermally comfortable room air temperature depending on the individual clothing and activity. In the future, this determined room air temperature will regulate the heating in a smart home. This should be user-specific and take into account not only clothing and activity, but also temperature preferences, age, gender and weight. Furthermore, it should be a dynamic system in which the room air temperature is adjusted immediately in the event of any changes of relevant parameters. In order to achieve this objective, a new way of calculating a thermally comfortable room air temperature must be found.

The focus lies on the room air temperature, since conventional controls for heating systems only use this as a variable. In addition, the room air temperature can more or less be influenced by controlling a heating system. Compared to radiation temperatures for example. 
In addition, a solution must be found to record correctly the individual clothing and the activity of the person in the room without negatively affecting their well-being. That also includes the integration of corresponding methods into a Smart Home System. In a first step, this was achieved for a test apartment with only one person in it.

\section{Methodology}

The basic idea to achieve this goal is to select a suitable index whose function is to evaluate a thermal environment and to determine a thermally comfortable air temperature with the help of a mathematical reformulation of this index.

For this purpose, various indices were taken into consideration which allow a statement on thermal comfort. Due to its high profile, the Predicted Mean Vote (PMV) process was ultimately selected to calculate a thermally comfortable air temperature depending on the individual clothing and activity. It should be noted that further indices have been identified which allow the calculation of such an air temperature. Based on the different calculation methods, the automated living space can be individualized by selecting a method that calculates air temperatures that correspond to the user's preferences. For example, if the user prefers a cooler indoor climate, the room air temperature is calculated with an index that calculates lower temperatures than the others under the same boundary conditions. The temperatures that can be determined with the various calculation methods are shown for illustration in Figure 1 for a degree of clothing of 0.5 clo and different degrees of activity.

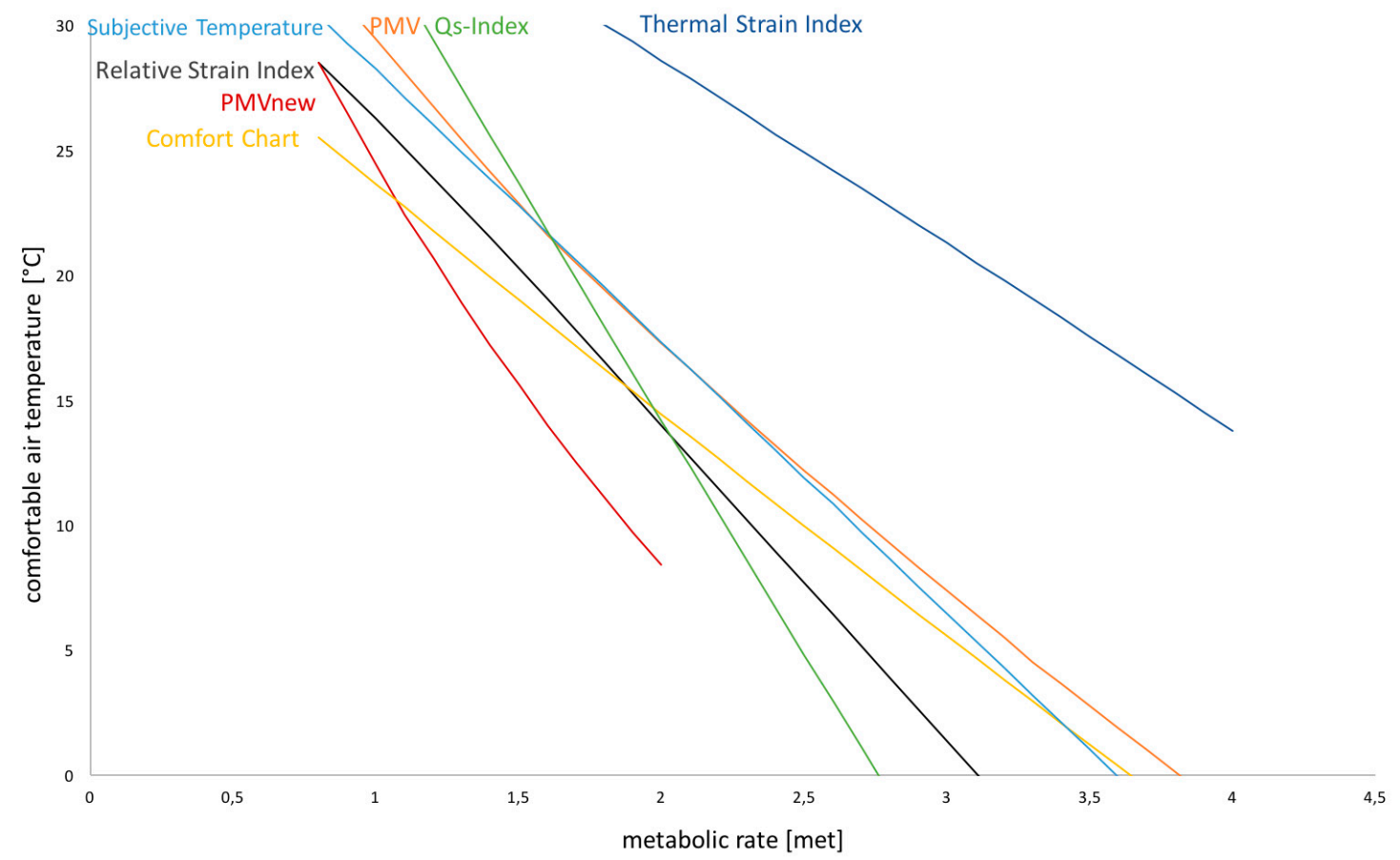

Figure 1. The comfortable room air temperature as a function of the metabolic rate $\left(1 \mathrm{met}=58.2 \mathrm{~W} / \mathrm{m}^{2}\right)$ and a clothing insulation of 0.5 clo.

The PMV process, originally developed by Fanger, is based on the energy balance equation of the human body. The method was included in the ISO 7730 for the evaluation of a thermal environment [11]. The PMV calculation allows the thermal environment to be evaluated on a scale divided into 7 levels from hot through neutral to cold. If the climate is assessed as neutral, the PMV is zero.

$$
\begin{aligned}
& \operatorname{PMV}=\left[0.303 \mathrm{e}^{(-0.036 \times \mathrm{M})}+0.028\right][(\mathrm{M}-\mathrm{W}) \\
&-3.05 \times 10^{-3}\left[5733-6.99(\mathrm{M}-\mathrm{W})-\mathrm{p}_{\mathrm{a}}\right]-0.42[(\mathrm{M}-\mathrm{W})-58.15] \\
&-1.7 \times 10^{-5} \mathrm{M}\left(5867-\mathrm{p}_{\mathrm{a}}\right)-0.0014 \mathrm{M}\left(34-\mathrm{T}_{\mathrm{a}}\right) \\
&\left.-3.96 \times 10^{-8} \mathrm{f}_{\mathrm{cl}}\left[\left(\mathrm{T}_{\mathrm{cl}}+273\right)^{4}-\left(\mathrm{T}_{\mathrm{r}}+273\right)^{4}\right]-\mathrm{f}_{\mathrm{cl}} \mathrm{h}_{\mathrm{c}}\left(\mathrm{T}_{\mathrm{cl}}-\mathrm{T}_{\mathrm{a}}\right)\right]
\end{aligned}
$$




$$
\begin{gathered}
\mathrm{T}_{\mathrm{cl}}=35.7-0.028(\mathrm{M}-\mathrm{W}) \\
-\mathrm{I}_{\mathrm{cl}}\left\{3.96 \times 10^{-8} \mathrm{f}_{\mathrm{cl}}\left[\left(\mathrm{T}_{\mathrm{cl}}+273\right)^{4}-\left(\mathrm{T}_{\mathrm{r}}+273\right)^{4}\right]+\mathrm{f}_{\mathrm{cl}} \mathrm{h}_{\mathrm{c}}\left(\mathrm{T}_{\mathrm{cl}}-\mathrm{T}_{\mathrm{a}}\right)\right\} \\
\mathrm{h}_{\mathrm{c}}=\left\{\begin{array}{c}
2.38\left|\mathrm{~T}_{\mathrm{cl}}-\mathrm{T}_{\mathrm{a}}\right|^{0.25} \text { if } 2.38\left|\mathrm{~T}_{\mathrm{cl}}-\mathrm{T}_{\mathrm{a}}\right|^{0.25}>12.1 \sqrt{\mathrm{v}_{\mathrm{a}}} \\
12.1 \sqrt{\mathrm{v}_{\mathrm{a}}} \text { if } 2.38\left|\mathrm{~T}_{\mathrm{cl}}-\mathrm{T}_{\mathrm{a}}\right|^{0.25}<12.1 \sqrt{\mathrm{v}_{\mathrm{a}}}
\end{array}\right. \\
\mathrm{f}_{\mathrm{cl}}=\left\{\begin{array}{c}
1.00+1.290 \mathrm{I}_{\mathrm{cl}} \text { if } \mathrm{I}_{\mathrm{cl}} \leq 0.078 \mathrm{~m}^{2} \mathrm{~K} / \mathrm{W} \\
1.05+0.645 \mathrm{I}_{\mathrm{cl}} \text { if } \mathrm{I}_{\mathrm{cl}}>0.078 \mathrm{~m}^{2} \mathrm{~K} / \mathrm{W}
\end{array}\right.
\end{gathered}
$$

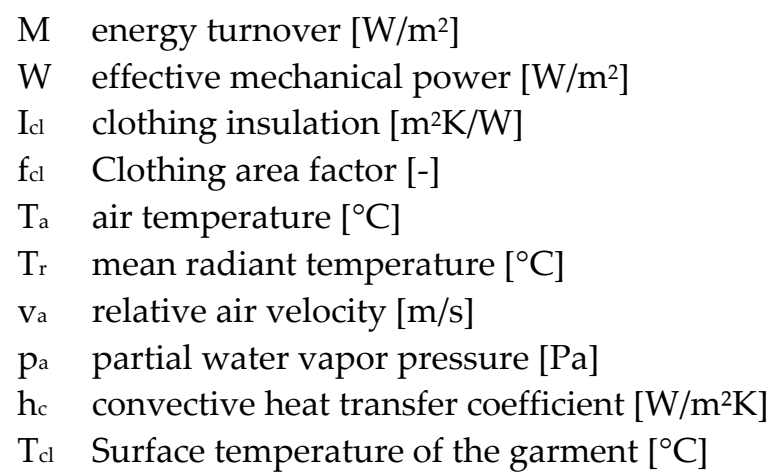

Accordingly, the aim is to determine a room air temperature which, under the existing climatic conditions of the room, as well as the consideration of clothing and activity, results in a PMV of zero. The general PMV formula is rearranged so that a thermal comfortable air temperature can be calculated under the condition that the PMV is zero. The condition that the PMV should be zero results from the fact that the indoor climate is considered thermally neutral and therefore comfortable when the PMV is zero. Since the air temperature is required to calculate the garment surface temperature, the vapor pressure and the convective heat transfer coefficient, an iterative solution process is used. For the first determination of these three variables, the current room air temperature is used; thus, a first thermally comfortable air temperature can be calculated on the assumption that the PMV equals 0. Then the convective heat transfer coefficient, the surface temperature and the vapor pressure are recalculated with the determined temperature. Subsequently, the usual PMV method is used to check whether the calculated air temperature, taking into account the climatic parameters actually prevailing in the room, fulfils the following condition.

$$
|\mathrm{PMV}| \leq \mathbf{0 . 0 0 0 1}
$$

The condition was chosen because Fanger (1970) stated that with a PMV of zero, only 5\% of people in a room consider the room climate to be thermally uncomfortable [12]. The Predicted Percentage of Dissatisfied is calculated for this purpose. If this parameter is now calculated with a PMV of $|0.0001|$, the PPD is also $5 \%$, so a better result cannot be achieved.

Figure 2 is designed to provide a better understanding of the calculation process. 


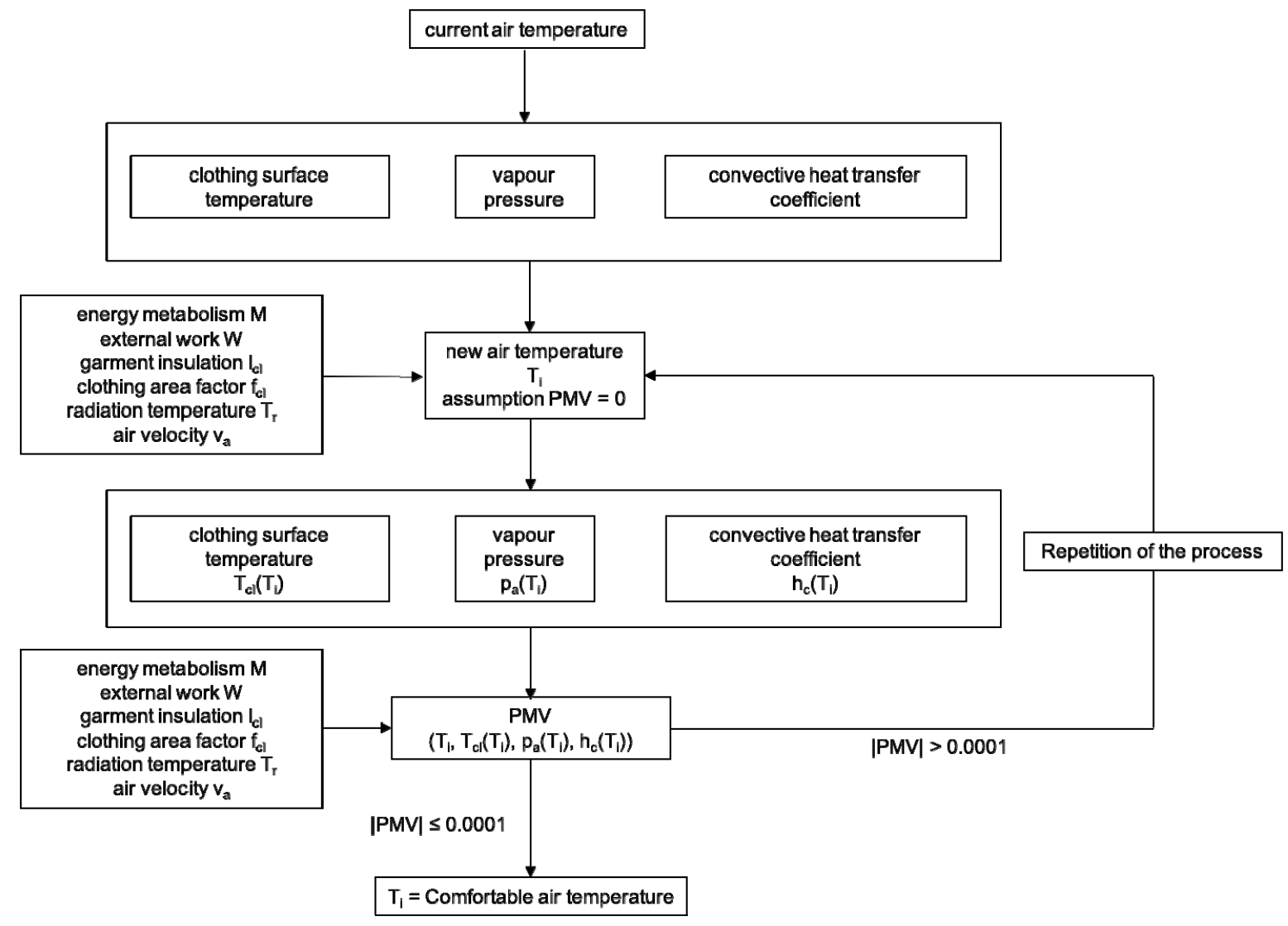

Figure 2. Process to calculate a thermally comfortable air temperature.

This calculation method can be easily programmed in Matlab and be used in a home automation system. To do this, the current air temperature, relative humidity, radiation temperature and air velocity in the room must be known. These values can be easily determined in a smart home by using sensors. In addition, however, the clothing worn and the activity or energy consumption of the person must be known. The calculation of a thermal comfortable air temperature on the basis of one of the other calculation methods shown in Figure 1 is based on similar iterative calculation methods. In the further course of the research, all methods will be weighed against each other and an attempt will be made to work out preferred methods for different user types. As the PMV process is the best known and covers a larger number of possible input variables, it was selected for the illustrative purpose of the procedure and therefor presented in detail in this paper.

To determine the thermally comfortable air temperature, the thermal insulation and thus the clo value of the worn clothing must be known. Clothing insulation is determined on the basis of a simple model. This represents the body as heat producer and the clothing layer as insulation as well as the boundary layer of the air on the clad body in the form of a heat transfer coefficient. Figure 3 shows the simple thermal model with a layer of cladding insulation according to Parsons (2014) [13].

By applying an equilibrium condition, the continuous heat production of the body creates a natural temperature gradient between the outside temperature of the clothing layers and the skin surface temperature as well as the body's core temperature. 


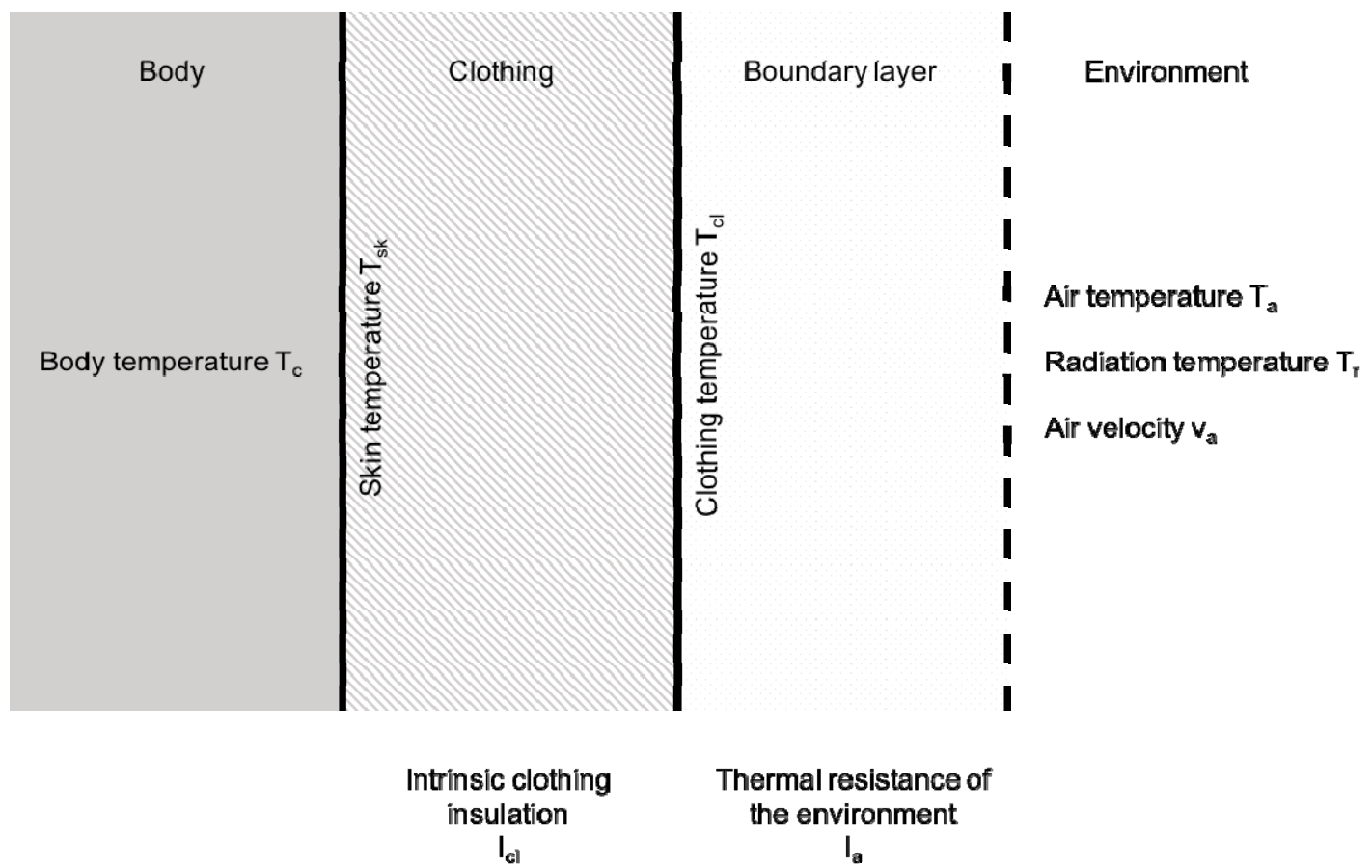

Figure 3. Simple thermal model with a layer of clothing insulation [13].

Three different methods were considered, which theoretically allow the determination of this value in an automated living space. This involves a system that works with a Radio Frequency Identification (RFID) technique, as well as a system with a thermal imaging camera and, as a last method, the prediction of the clothing worn in the interior based on the outside air temperature data.

With the RFID technology, individual transponders and a reader communicate via radio waves. The distance at which the two components can communicate with each other depends on the frequency range of the respective system. A system that operates in the ultra-high frequency range and that allows communication up to a distance of five meters was chosen to carry out this study. The transponders, which are equipped with a chip and an antenna, can be sewn into the individual garments. A receiver detects the transponders when a person, who is wearing the clothing equipped with transponders, is walking past them. For example, each door that connects one room to another can be fitted with such a reader, and the home automation system knows at all times what clothes the person in the room is wearing. Each of these transponders is marked with a unique Electronic Product Code (EPC). Each individual garment is recorded in a database, with the EPC assigned to a clo value corresponding to the garment. These clo values, which can be taken from the ISO 9920 for example, represent the specific thermal insulation of each garment $\left(1 \mathrm{clo}=0.155 \mathrm{~m}^{2} \mathrm{k} / \mathrm{W}\right)$ [14]. Based on the individual clo values of each garment, the clo value of the entire garment combination $\left(\mathrm{I}_{\mathrm{cl}}\right) \mathrm{can}$ now be calculated using a Matlab script stored on the server. This script includes the given formula taken form the ISO 9920.

$$
\begin{gathered}
\mathrm{I}_{\mathrm{cl}}=0.835 \times \sum \mathrm{I}_{\mathrm{cl}(\text { clothing item })}+0.161 \\
\mathrm{I}_{\mathrm{cl}}=0.835 \times(\mathrm{clo} 1+\operatorname{clo} 2+\text { clo } 3+0.02+0.03)+0.161
\end{gathered}
$$

Several assumptions were made for the practical implementation.

1. a user always wears socks (0.02 clo)

2. a user always wears underwear ( 0.03 clo for men and 0.04 clo for women)

3. a user always wears 3 garments (trousers (clo1), T-shirt (clo2), sweater (clo3)) in winter

4. a user always wears 2 pieces of clothing (trousers (clo1), T-shirt (clo2)) in summer

For the tests in the test apartment, 25 garments were equipped with RFID tags. Their clothing type, EPC codes and clo values were read into a database, making it possible to read out the user's 
clothing as he walked past the RFID antenna and to calculate the current clothing level according to the above relationship.

A disadvantage of this method is that the RFID system does not differentiate whether a person actually wears the clothes or only holds them in his or her hand. With the help of a thermal imaging camera, both the skin temperature and the surface temperature of the garment could be determined. These two parameters also theoretically allow the clo-value of the garment worn to be determined [15]. Within the scope of this work, this method was not installed and tested in a test apartment, in contrast to the determination of garment insulation with an RFID system. Only test trials were carried out with individual garment combinations and individual persons.
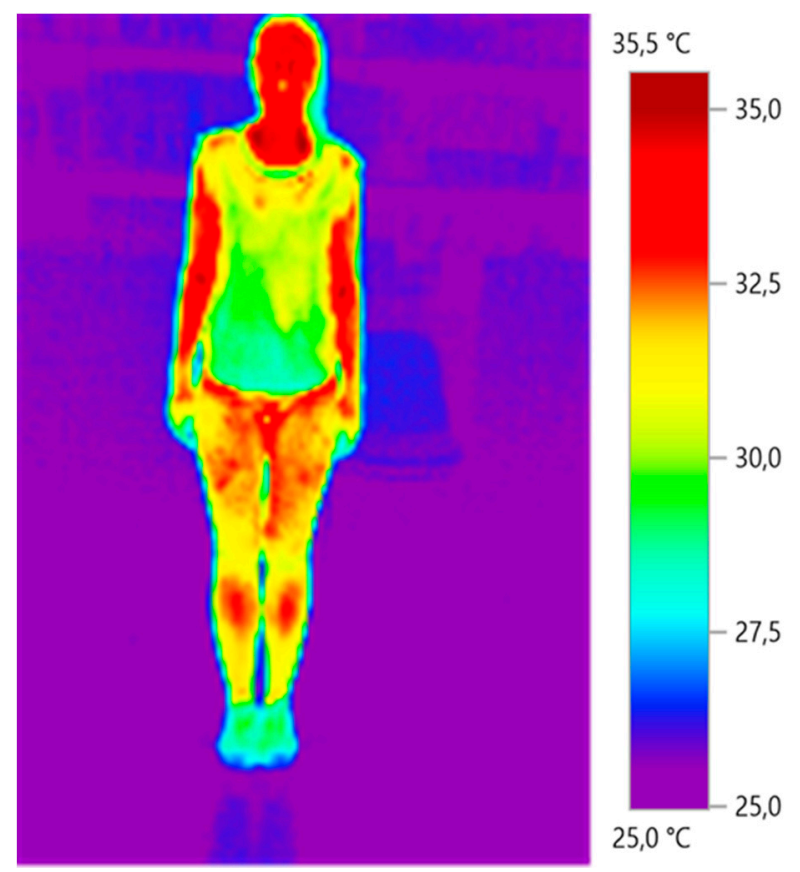

Figure 4. Exemplary recording with the thermal imaging camera.

For this purpose, a thermal image, as shown in figure 4, was taken of several people. To determine garment insulation using a thermal imaging camera, a number of formulas are required that take into account both body temperature and garment surface temperature. These serve as input variables for the following equation, which must eventually be fulfilled [15].

$$
0.305 \mathrm{I}_{\mathrm{cl}}^{2}+\mathrm{I}_{\mathrm{cl}}-\frac{1}{0.155 \times \mathrm{C}_{\text {orr }, \text { tot }}}\left\{\propto+\mathrm{I}_{\mathrm{a}}\left(\mathrm{C}_{\text {orr,ia }}-\mathrm{C}_{\text {orr }, \text { tot }}\right)\right\}=0
$$

This equation can only be solved in an iterative process, for this purpose a Matlab script was written which will run automatically on the server of the home automation system in the future. Both the clothing temperature and the skin temperature were recorded with an ordinary thermal imaging camera. In addition, the air temperature, the radiation temperature and the air velocity in the room are also required for the calculation, these were recorded with sensors. Superficial tests have already shown that the determination of the clo value with a thermal imaging camera does not always lead to the correct result. Thus, the clo values calculated with the algorithm partly deviated widely from those found in ISO 9920. The results of this test for 2 people are shown in Table 1.

Table 1. Results of thermal imaging insulation determination.

\begin{tabular}{ccccc}
\hline Person & Clothing Temperature $\left[{ }^{\circ} \mathrm{C}\right]$ & Skin Temperature $\left[{ }^{\circ} \mathrm{C}\right]$ & clo-Value (Algorithm) & clo-Value (ISO9920) \\
\hline 1 & 30.4 & 33.4 & 0.76 & 0.56 \\
\hline 2 & 30.5 & 32.9 & 0.62 & 0.56 \\
\hline
\end{tabular}


For improved understanding, Person 1 was wearing a t-shirt and trousers made of certain materials, the algorithm calculated a clo value of 0.76 for this clothing combination, while based on the values found in ISO 9920 for these particular garments, a clo value of 0.56 is obtained.

The last method is based on a formula presented by Morgan and de Dear (2003). It allows the calculation of the average clo value of clothing worn by people indoors on a given day. The calculation takes into account the maximum outdoor air temperature predicted for the day in question and the mean value of the outdoor air temperature of the previous day. [16]

$$
\operatorname{clo}(\text { Mean Value })=1.15-0.0164 \times T_{G}-0.0178 \times T_{H}
$$

$\mathrm{T}_{\mathrm{G}}$ actually observed mean outdoor temperature of the day before $\left[{ }^{\circ} \mathrm{C}\right]$

$\mathrm{T}_{\mathrm{H}}$ predicted maximum outdoor temperature for the observation day $\left[{ }^{\circ} \mathrm{C}\right]$

This connection is justified by the fact that people basically assume when choosing their clothes that the outside temperature today will be similar to yesterday. In addition, people are influenced by the weather forecast they hear on the radio or are told by their smartphone at the time when the dress selection takes place. In the context of this work, the above formula was reviewed for 10 days with a group of 10 people. However, the mean value of the outdoor air temperature over $24 \mathrm{~h}$ from the previous day was not used but only the mean outdoor air temperature in the period from 7 a.m. until 7 p.m. This is justified by the fact that this is the period in which people are not at home and perceive the outside air temperature. The results of this verification are shown in Figure 5.

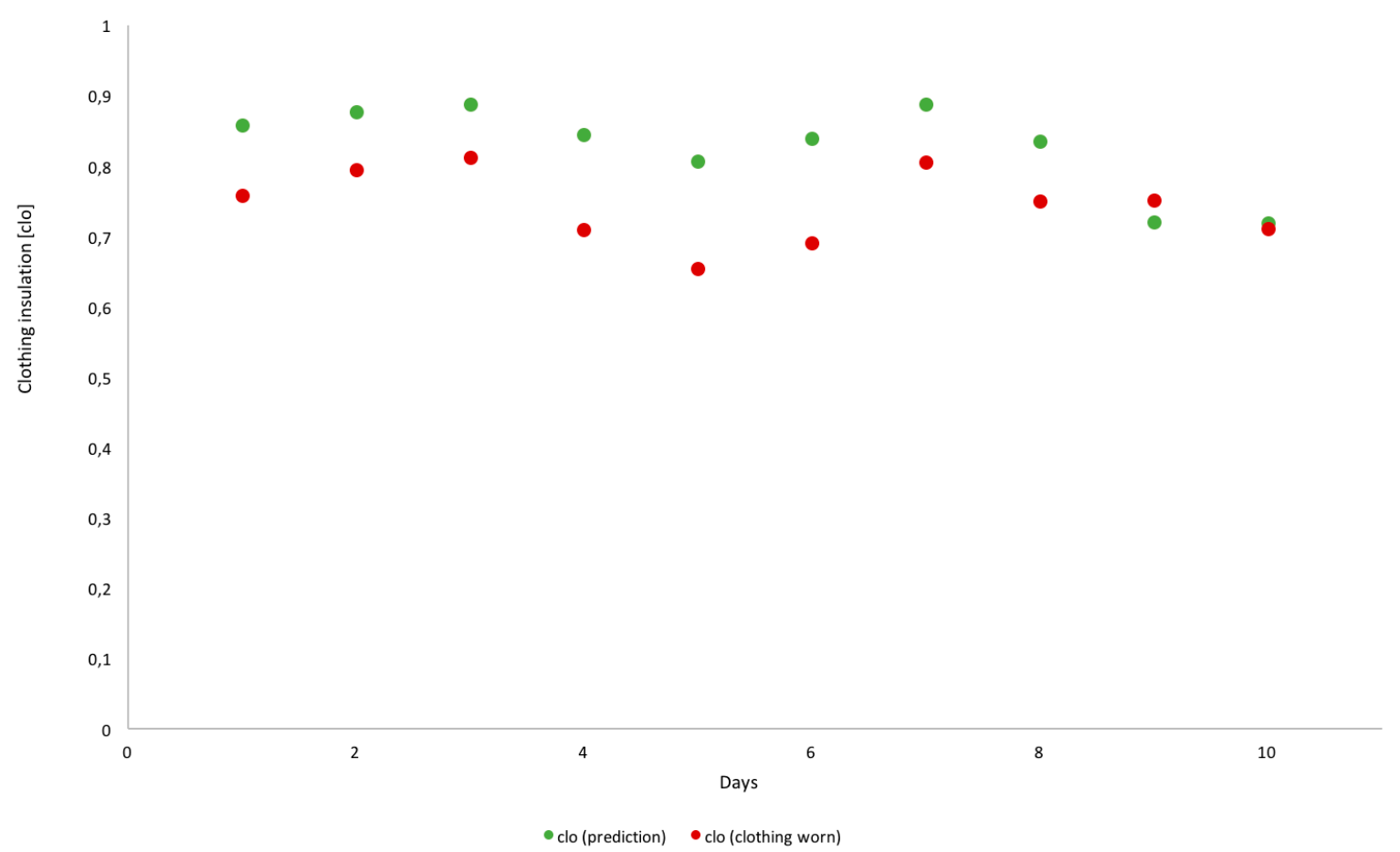

Figure 5. Comparison of the calculated average clo value $(12 \mathrm{~h})$ with the average clo value of the clothing worn.

Figure 5 shows a clear correlation between the clo value calculated on the basis of the outside temperature and the clo value of the clothing actually worn. The lower the outside temperature, the higher the clo value of the clothing worn. The clo value of the clothing actually worn is the mean value of the clothing combinations worn by all persons involved in the study. It was clearly visible that this relation between the two clo-values is greater for persons who can choose their clothing individually than for people who have to wear certain clothing for their work and thus wear a suit 5 days a week, for example. Over the entire 10 test days the same formula was used to calculate the 
clo-values, that the values on day 9 and 10 are closer to each other has resulted by chance, an obvious reason for this event has not yet been identified.

Finally, it can be said that the degree of clothing can be determined with the RFID system. In the further process, however, the algorithm must be extended in such a way that more than 3 garments are recognized and also less than 3 garments in winter lead to a calculation. The calculation using a thermal imaging camera has proven to be too error-prone. For the future, a combination of the two methods seems to make sense for a stable reliable operation of garment determination. In order to obtain even more reliable results, the clo values which are calculated on the basis of the outdoor temperature data could be calibrated with those determined by the other two systems.

In a final step, the metabolic rate required to calculate a thermally comfortable air temperature is determined. The metabolic rate depends on the activity performed and is a measure of a person's energy consumption. The metabolic rate has always been assumed for previous calculations of thermal comfort with standard values for single activities, which can be taken from the ISO 8996. In contrast to this and because it is hardly possible to determine the exact activity of a person in a smart home with motion sensors, the metabolic rate is not determined on the basis of the activity performed, but with the help of the person's heart rate. To use the heart rate dynamically, it is recommended to utilize a smart wearable such as a smart watch or a fitness tracker that allows the heart rate to be recorded and simultaneously feed it into a database on the home automation server. When carrying out this work in a concrete test room, no solution could be found to feed the heart rate into the server immediately after recording it with the Smart Wearable on the wrist. In the future, however, this will certainly be possible with appropriate applications. In initial tests, the heart rate was transmitted to the automation server via a Smart Blood Pressure Monitor. A program has been written that determines the energy consumption of the person in question depending on the recorded heart rate, gender, age and weight. This calculation method is based on a method described in the ISO 8996.

\section{Conclusions and Future Work}

The presented method allows to calculate a theoretically thermal comfortable air temperature depending on the individual clothing and activity, as well as the physical boundary conditions prevailing in the room (relative air humidity, radiation temperature, air velocity). It would be conceivable to couple this temperature calculation to a motion sensor. If a sensor detects a movement in the room, something may have changed in the person's activity and the optimum room air temperature must be recalculated. Next, the calculated room air temperature is compared with the current temperature prevailing in the room and the heating or cooling can then be controlled to set the appropriate temperature in the room. The same method could also be used to regulate the ventilation in a room. In this case instead of calculating an air temperature with the PMV method, a theoretically comfortable air velocity can be calculated.

Both the determination of the individually worn clothing and the metabolic rate require further optimization. As far as clothing is concerned, a method should above all be found that allows the insulation of clothing to be determined with sufficient certainty; this is not yet the case due to the fact that the system cannot distinguish which garments are actually worn. When determining the metabolic rate, a suitable interface solution must be found in the future to transfer the data directly from the Smart Wearable to the server.

However, a precise evaluation of the entire process is still missing. An RFID system was installed in the test apartment which worked for individual tests. In order to obtain statistically usable results, this system would have to be tested with at least 12 persons. Each of these persons would have to equip 25 to 30 garments with RFID tags. In addition, in order to test it under real conditions, several apartments would have to be equipped with an RFID system as well as with the sensors for recording the physical influencing variables. All this has not been feasible in the context of this work, both for time and cost reasons. The same applies to a more precise examination of the determination of the clo values with a thermal imaging camera. The long-term goal is to carry out this evaluation and to use deep learning algorithms to control the heating and cooling system in an apartment without any 
intervention of the residents. To realize all this, long trial periods and a lot of user feedback to adjust the deep learning algorithms would be needed.

The long-term goal is to carry out evaluations of the method with long-term test periods and several users. In addition to measurement data, user feedback on thermal comfort will also be recorded and the method will be improved with the help of deep learning algorithms to such an extent that a concrete individual assessment of a user's sense of comfort in the living space is possible and, based on this, an individual temperature control of the living space can take place.

Furthermore, it will be necessary to check how far the new system can be used if there is more than one person in the room under consideration.

Nevertheless, a method was found that allows a dynamic regulation of the room air temperature in a Smart Home depending on the individual clothing and the respective activity.

\section{References}

1. Frohn, B.; Ranft, F. Natürliche Klimatisierung, Energieagentur NRW; Springer: Basel, Switzerland, 2004.

2. Benzinger, T.H.; Mayer, E. Definition der thermischen Behaglichkeit, Fraunhofer Institut für Bauphysik, IBP Mitteilung; Fraunhofer Institut für Bauphysik: Stuttgart, Germany, 1986; Volume 115.

3. Mayer, E. Physik der thermischen Behaglichkeit, Fraunhofer Institut für Bauphysik, Sonderdruck aus Physik in unserer Zeit; Fraunhofer Institut für Bauphysik: Stuttgart, Germany, 1989.

4. Sedlbauer, K.; Holm, A.; Künzel, H.M.; Leistner, P.; Breuer, K. Raumklima und Innovation: Eine Aufgabe der Bauphysik. Zeitschrift für Wärmeschutz, Kälteschutz, Schallschutz, Brandschutz 2006, 51, 9-16.

5. Satpathy, L. Smart Housing: Technology to Aid Aging in Place. New Opportunities and Challenges. Ph.D. Thesis, Mississippi State University, Starkville, MS, USA, 2006.

6. Aldrich, F.K. Smart Homes: Past, Present and Future, Inside the Smart Home; Springer: London, UK, 2003; pp. $17-39$.

7. Vazquez, F.I.; Kastner, W. Thermal Comfort Support Application for Smart Home Conrtol, Ambient Intelligence: Software and Applications. In Proceedings of the 3rd International Symposium on Ambient Intelligence (ISAml), Salamanca, Spain, 23-30 March 2012; Springer Verlag: Berlin, Germany, 2012.

8. Vazquez, F.I.; Kastner, W. Usage profiles for sustainable buildings. In Proceedings of the 15th Conference on Emerging Technologies and Factory Automation (ETFA), Bilbao, Spain, 13-16 September 2010.

9. ISO 8996. Ergonomie der thermischen Umgebung: Bestimmung des körpereigenen Energieumsatzes (ISO 8996:2004); Deutsche Fassung EN ISO 8996:2004; International Organization for Standardization: Geneva, Switzerland, 2004.

10. Kim, H.H.; Lee, K.C.; Lee, S. Location-based human adaptive air conditioning by measuring physical activity with a non-thermal-based indoor positioning system. Build. Environ. 2013, 62, 167-173.

11. ISO 7730. Ergonomie der Thermischen Umgebung: Analytische Bestimmung und Interpretation der Thermischen Behaglichkeit durch Berechnung des PMV- und des PPD-Indexes und Kriterien der Lokalen Thermischen Behaglichkeit (ISO 7730:2005); Deutsche Fassung EN ISO 7730:2005; International Organization for Standardization: Geneva, Switzerland, 2005.

12. Fanger, P.O. Thermal Comfort: Analysis and Applications in Environmental Engineering; Danish Technical Press: Copenhagen, Denmark, 1970.

13. Parsons, K. Human Thermal Environments: The Effects of Hot, Moderate, and Cold Environments on Human Health, Comfort, and Performance, 3rd ed.; CRC Press: Boca Raton, FL, USA, 2014.

14. ISO 9920. Ergonomie der thermischen Umgebung: Abschätzung der Wärmeisolation und des Verdunstungswiderstandes einer Bekleidungskombination (ISO/DIS 9920:2004); Deutsche Fassung prEN ISO 9920:2004; International Organization for Standardization: Geneva, Switzerland, 2004.

15. Lee, J.H.; Kim, Y.K.; Kim, K.S.; Kim, S. Estimating Clothing Thermal Insulation Using an Infrared Camera. Sensors 2016, 16, 341.

16. Morgan, C.; de Dear, R. Weather, clothing and thermal adaptation to indoor climate. Clim. Res. 2003, 24, $267-284$. 